\title{
Constraints on Applying Disability Identity Card: A Study from Roshi Rural Municipality from Midhill, Nepal
}

\author{
Hemanta Dangal, ${ }^{* 1}$ Supa Paneru, ${ }^{2}$ Baijayanti Mala Pokhrel ${ }^{3}$ \\ ${ }^{1}$ Save the Children- Nepal Country Office \\ ${ }^{2}$ Western Norway University of Applied Sciences, Norway \\ ${ }^{3}$ Ratna Rajya Laxmi Campus, Tribhuwan University, Nepal \\ *Corresponding author's email: hemantadangal@yahoo.com \\ DOI: https://doi.org/10.3126/jsp.v1i0.38213
}

\section{A R T I C L E I N F O}

Article history:

Received 23 Sept. 2020

Accepted 22 Nov. 2020

Keywords:

Distance

ID card

Lack of knowledge

Persons with Disability (PwDs)

Social security

\section{A B S T R A C T}

Disability Identity Card (ID)is the key document issued for individuals with disabilities and qualifies a person as a recipient of disability allowance, a Social Security Programme of the Government of Nepal. Based on primary data collected using household questionnaire survey and in-depth interviews from Roshi Rural Municipality in Midhill Nepal, this paper aims to assess the socio-cultural backgrounds and major constraints in applying and acquiring the Disability ID card. Findings show that lack of knowledge about the ID card, its benefits and the application process are found to be the major constraints in acquiring it. Those who know about the application process have also been facing difficulties such as longer travel distance to district headquarter, lengthy and ambiguous processes, lack of money, and lack of supporting documents. The state restructuring and federalisation was found to be an opportunity in terms of the active roles that the local municipal government have played wherein more person with disability ( $P w D s)$ have approached for the card.

\section{Introduction}

The Government of Nepal has started providing Disability Identity Card (ID) to person with disability (PwD) from 2009 as per the provision of Disability ID Card Distribution Directive 2065 (2009). However, the bill on disability was already introduced by the government in 2006. The Directive provisioned four categories of disabilities which are also provisioned in the Act Relating to Rights of Person with Disabilities, 2074 (2017), and its first amendment 2018. These categories are i) "profound disability - a person who is in such a condition that he or she has difficulty with performing his or her day-to-day activities even with continuous support of others, ii) severe disability - a person who is in such a condition that he or she needs support of others continuously to perform personal activities and involve in social activities, iii) moderate (mid-level) 
disability - a person who is in such a condition that he or she can regularly participate in his or her daily activities and in social activities if physical facility is available, environmental barrier is ended or education or training provided, and iv) mild disability - a person who is in such a condition that he or she can regularly participate in his or her daily activities and social activities if there exists no physical and environmental barrier" (Government of Nepal, 2017:33-34).

The ID card is the only key document that qualifies the person to be eligible to register for disability allowance provided by the government. The social security programme of Nepal has provisioned the social security allowance for two categories of PwDs - profound and severe disability, also commonly termed as category $\mathrm{A}$ and category B disability.

The government had authorized the district level office of the Ministry of Women, Children and Senior Citizen for providing the ID card in the respective districts. This provision continued in this institutional set up until the commencement of the new federal set up authorization of disability identification and card distribution from respective local units in November 2018. As per the new institutional set up, there are three tiers of government -local, provincial and federal government. With the new set up, there are 753 local units including rural municipalities and municipalities. Within this new structure, the local government is responsible to identify and distribute the disability ID card within the respective municipality. As per this institutional provision, Roshi Rural Municipality had adapted and endorsed its own procedure to identify and distribute disability ID card on December 2018. Following this, the municipality has identified individuals with disability and distributed the ID card.

Despite being eligible, majority of the people have abstained in acquiring the disability ID card in Nepal (Eide et al., 2016). This can primarily be attributed to lack of knowledge among the people with disability or their family members about the service available at district headquarter or elsewhere (Poudyal et al., 2018). In addition, tedious application process related to where and how to apply and lack of appropriate documents are some of the causes driving lack of acquisition of the IDs (Holmes et al., 2018). The supplementary information discussed in the initial report on implementation of the Convention on the Rights of Persons with Disabilities also highlights the barriers at the service level (NFDN, 2018). The report points out that the office which is responsible for identifying PwDs are not well-equipped to determine the level and type of disability because of low technically sound human resources. The report further adds that it is even more difficult to receive disability ID card for individuals having intangible disability. Kidd (2017) argues that limited administrative capacity to implement the programme can be a barrier for PwDs in accessing facilities provided by disability specific programmes. Likewise, Morgon et al. (2019) in their study in Tahanun district argues that there are different factors including geographic accessibility, financial accessibility, determining eligibility, understanding the application process, awareness and perceived utility of programmes and compliance among service providers, which is refraining the PwDs from acquiring disability ID cards and associated social security assistance.

Human Rights Watch (2011), in its study highlights that children having disability are being excluded from disability ID card due mainly to long distances that they need to travel to the district headquarter to apply for the card. Similarly, high transportation costs that their family members need to bear and negative attitudes among the parents who feel that acquiring such cards would further marginalise their children are some of the other 
factor influencing in applying for the ID cards. In countries with similar socio-economic context to Nepal for instance Bangladesh, the family member's knowledge about the existing government services has been acting a barrier in terms of accessing support for the children from the government (Nuri et al., 2020). In this context, this paper aims to explore the constraints faced by PwDs in acquiring the Disability ID card. In doing so, this paper specifically attempts to answer the question on "why people with disability have not received ID card even though they were eligible before distributing it from the municipality?

\section{Methods and Materials}

Roshi Rural Municipality is one of the 13 municipalities situated in Kavrepalanchok district. The district is borders with Kathmandu and is situated $60 \mathrm{~km}$ east from the valley. Despite being close to the valley, this municipality is located in a relatively remote area of the district. It is partly linked to the BP highway that connects Kathmandu valley with the southern Terai. As per Roshi municipality's profile 2075, the total population of municipality is around 40,000 among which majority are Tamangs. The literacy rate of the municipality is 78 per cent and the major occupation includes agriculture and wage labour.

Records at Roshi Municipality shows that it has proactively identified and provided disability ID cards to 222 individuals within the municipality in 2019. Out of the total individuals identified, 68 new recipients of the ID card were selected as the sample for the purpose of this study. The sample size was fixed considering 95 per cent confidential level and 10 per cent confident interval. The sample was selected randomly by using the lottery method. Out of the total sample households, 53 questionaries were administered to the family members of the PwDs and 15 questionnaires were administered to individuals with disability.

The paper is based on primary data collected using household questionnaire survey conducted in 2020. Semi-structured questionnaires comprised of details including sex, age, education, occupation, category of identity cards, their family members' information, and primarily the reason for not

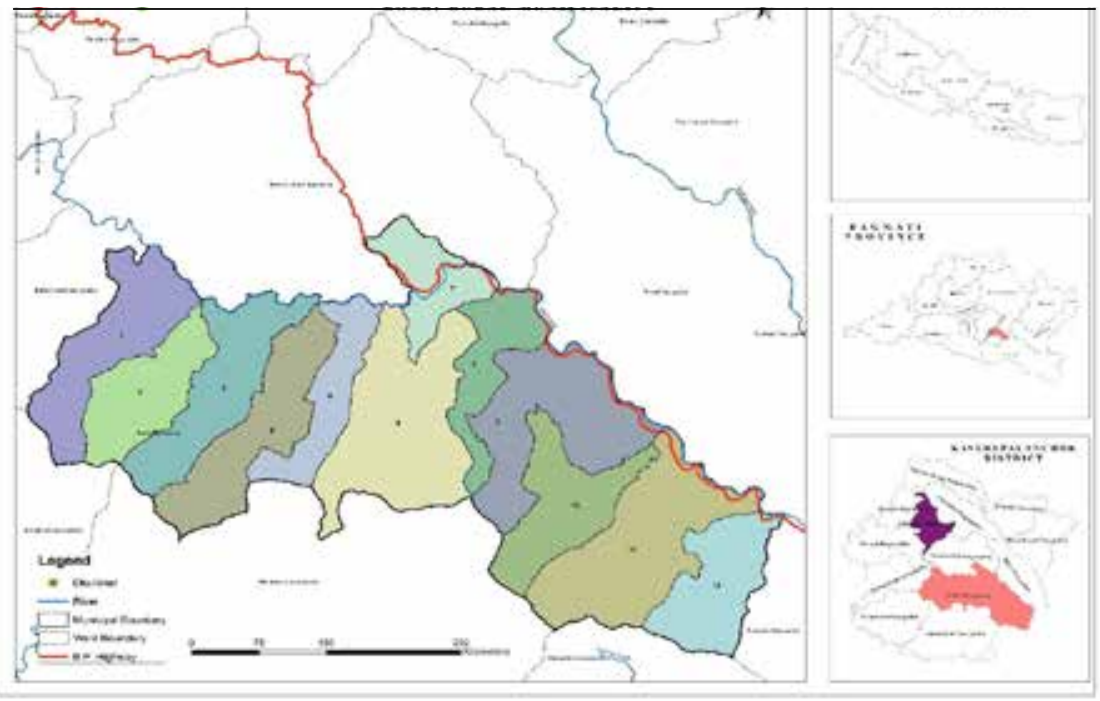

Figure 1: Location map of Roshi Rural Municipality 
applying for the card previously from the district office. After completing the household survey, a preliminary analysis was carried out. It was found that 23 respondents or their family members had knowledge about where to approach for the disability ID card, while rest of the respondents were unaware about it. Thus, these 23 respondents were selected for in-depth interviews. The in-depth interviews were mainly focused to explore the reasons for not applying/getting disability ID card despite having knowledge about the process.

Quantitative data was tabulated in excel sheet and appropriate tables and figures were produced. Qualitative data were transcribed, and the texts were categorised. A simple statistical analysis was carried out and descriptive analysis of the qualitative information was conducted. The findings were presented in tables, figures, and diagrams.

\section{Results and Discussion}

\subsection{Background characteristics of PwDs}

\subsubsection{PwDs by ID card category}

It was observed that about 28 per cent of PwDs fell in the category A followed by 43 per cent in category B. These two categories are also known as 'profound' and 'severe disability, and are recipients of red color and blue color ID cards respectively. These two categories of PwDs covered about 71 per cent who are entitled to the social security allowance. It is important to mention that about two third in the category B were female while the male-female ration ratio in category $A$ did not have much difference (Table 1).

Table 1: Number of respondents by PwDs category by gender

\begin{tabular}{|l|c|c|c|c|}
\hline $\begin{array}{c}\text { Category } \\
\text { of PwDs }\end{array}$ & Female & Male & Total & Per cent \\
\hline Ka (A) & 9 & 10 & 19 & 27.94 \\
\hline Kha (B) & 10 & 19 & 29 & 42.65 \\
\hline Ga (C) & 5 & 14 & 19 & 27.94 \\
\hline Gha (D) & 1 & 0 & 1 & 1.47 \\
\hline Total & $\mathbf{2 5}$ & $\mathbf{4 3}$ & $\mathbf{6 8}$ & $\mathbf{1 0 0 . 0 0}$ \\
\hline
\end{tabular}

Source: Field survey, 2020.

\subsubsection{Years of schooling of PwDs}

The educational status of PwDs and their family members is illustrated in figure 2 . Out of total samples, 68 per cent were illiterate, 15 per cent just literate who can only read and write, 10 per cent have received basic education - up to grade 8 , and the remaining seven per cent have completed secondary education. The highest years of schooling of PwD's family members was found to be 15 whereas the highest years of schooling attended by PwDs was only 12 . The average years of schooling attended by PwDs was

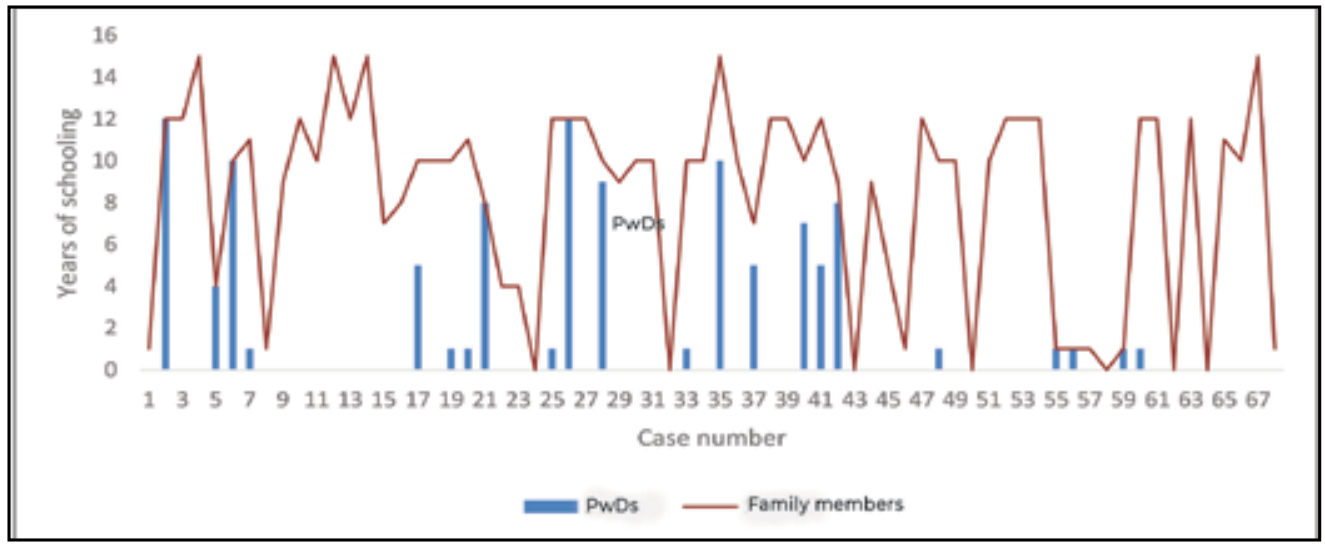

Figure 2: PwD's versus family member's years of schooling 
1.54 while it was 8.27 years for their family members. The figures show the differences in in years of education received by the PwDs compared to their family members (Figure 2).

\subsubsection{Disability identification and years waited to get ID card}

Figure 3 shows the current age of a disable person and number of years of their disability. The data shows that almost half of the PwDs were disabled by birth. Around 22 per cent of the people had noticed when they were between the age of 1-18 years while 19 per cent had disability when they were between 19 and 60 years of age. Likewise, seven per cent had become disabled after the age of 60 .
Table 2: Years PwDs waited to receive the ID card

\begin{tabular}{|c|c|c|c|c|}
\hline \multirow{2}{*}{$\begin{array}{c}\text { Years } \\
\text { waited }\end{array}$} & \multicolumn{3}{|c|}{ Number of PwDs } & \multirow{2}{*}{ Percent } \\
\cline { 2 - 4 } & Female & Male & Total & \\
\hline 3 & 1 & 1 & 2 & 2.94 \\
\hline 6 & & 2 & 2 & 2.94 \\
\hline 7 & & 1 & 1 & 1.47 \\
\hline 8 & & 1 & 1 & 1.47 \\
\hline 10 & 1 & 1 & 2 & 2.94 \\
\hline 11 & 23 & 37 & 60 & 88.24 \\
\hline Total & $\mathbf{2 5}$ & $\mathbf{4 3}$ & $\mathbf{6 8}$ & $\mathbf{1 0 0 . 0 0}$ \\
\hline
\end{tabular}

Source: Field survey, 2020.

\subsubsection{PwDs prevalence by generation}

The social and family sett up has appeared to be an important aspect of the PwDs. Nepal

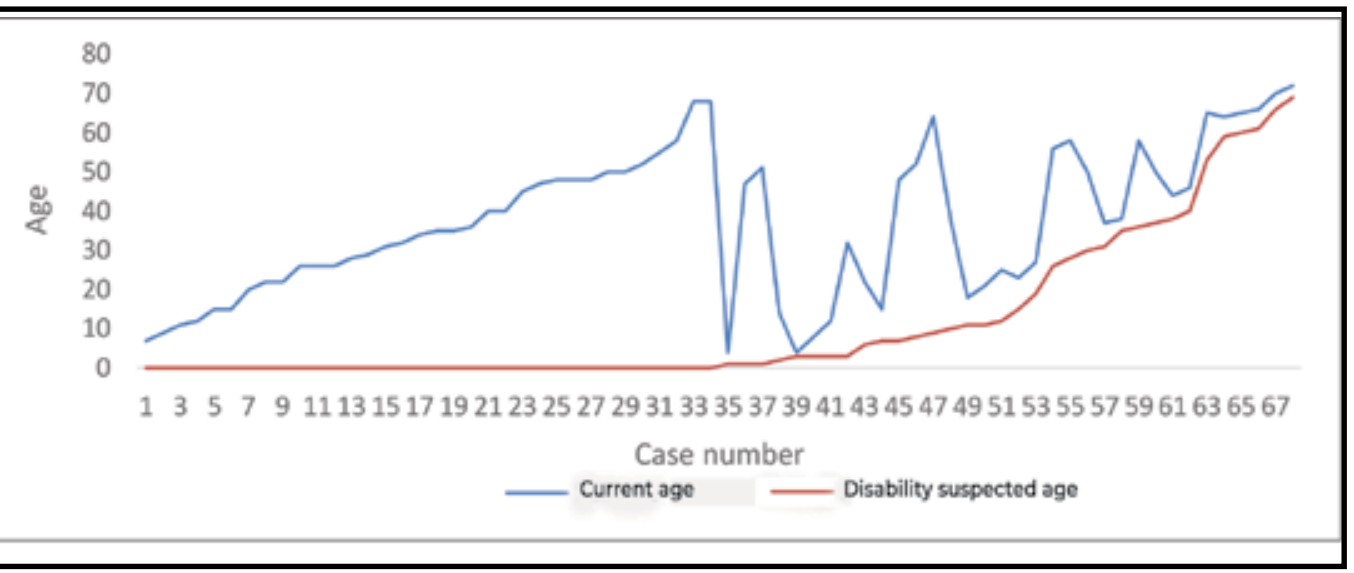

Figure 3: PwDs current age versus disability suspected age

Taking 2009 as a reference year on start of distribution of disability ID cards, number of years that the PwDs had to wait to acquire the ID card was assessed. The findings show that around 88 per cent of PwDs waited for 11 years to acquire their ID card. In other words, they only got the ID card after 11 years of the initiation on distribution of the card. In terms of gender, it was observed that there is not much difference between male and female in identifying and acquiring the card (Table 2). has 125 caste/ethnic groups wherein Tamang are largely distributed in the central part of the country and is also the dominant group in the study area. Out of the total study population, leaving one household, all are Tamangs. Furthermore, the generation wise presence of disability is an interesting thing to observe. The data shows that 66 per cent of PwDs belonged of second generation, 12 per cent belonged to the first /grandparent generation and remaining 22 per cent belonged of the third or grandchild generation. Importantly, 
about 35 per cent of the second generation PwDs were not married though they are above the age of 20 years (Figure 4 ).

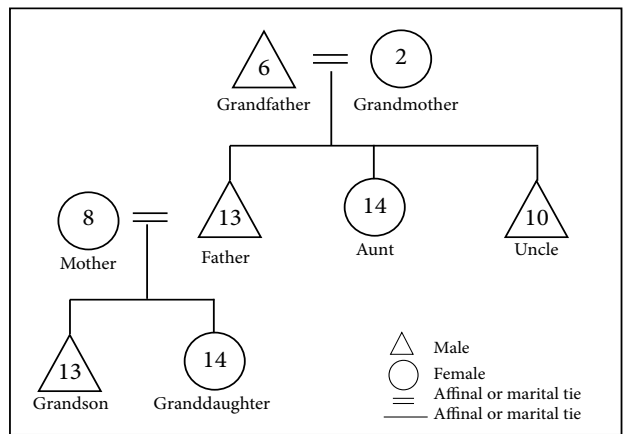

Figure 4: PwDs by kinship ties (Adopted from Schusky, 1972)

\subsubsection{Employment and participation of $P w D s$}

Regarding the employment, about 75 per cent have not been involved in any job while 17 per cent in agriculture, 4 per cent in local business and remaining are involved in private job. Participation in various social activities and events shows the degree of their socialisation. During the field survey question regarding whether PwDs take part in social events like marriage in their village or not was asked. Findings show that about 50 per cent of the PwDs usually take part in social events. Differences was observed in terms of gender wherein 56 per cent of male took part in social events in the village while only 40 per cent female attended such activities (Table 3)

Table 3: Participation by PwDs in social events

\begin{tabular}{|l|c|c|c|c|}
\hline \multicolumn{4}{|c|}{ Participation of PwDs in social events } \\
\hline Gender & No & Seldom & Yes & $\begin{array}{l}\text { Grand } \\
\text { Total }\end{array}$ \\
\hline Female & 13 & 2 & 10 & 25 \\
\hline Male & 18 & 1 & 24 & 43 \\
\hline $\begin{array}{l}\text { Grand } \\
\text { Total }\end{array}$ & $\mathbf{3 1}$ & $\mathbf{3}$ & $\mathbf{3 4}$ & $\mathbf{6 8}$ \\
\hline
\end{tabular}

Source: Field survey, 2020.

\subsection{Constraints for not applying the ID card}

A number of constraining factors in applying the disability ID card was identified. Findings show that a few PwDs had made a number of attempts in applying for the card especially before its distribution from the local unit/ municipality. About 87 per cent PwDs had received the card in their first attempt from the municipality. However, 14 per cent attempted to acquire it from the district office, but were not able to apply (Table 4).

Table 4: Number of attempts PwDs had for applying ID card

\begin{tabular}{|l|r|r|r|}
\hline \multirow{2}{*}{ Gender } & \multicolumn{3}{|c|}{ Number of attempts } \\
\cline { 2 - 4 } & \multicolumn{1}{|l|}{ First } & \multicolumn{1}{|c|}{ Second } & Third \\
\hline Female & 23 & 2 & 0 \\
\hline Male & 36 & 6 & 1 \\
\hline Grand Total & 59 & 8 & 1 \\
\hline Per cent & $\mathbf{8 6 . 7 6}$ & $\mathbf{1 1 . 7 6}$ & $\mathbf{1 . 4 7}$ \\
\hline
\end{tabular}

\subsubsection{Knowledge about ID card, its benefit, and the process}

Lack of knowledge about the disability ID card, its benefit coverage, and the processes of applying and acquiring it was found to be the major constraining factors. The findings show that 53 per cent PwDs had no knowledge about the ID card before acquiring it from the local municipality in 2019. Similarly, about 54 per cent PwDs had no knowledge about the various benefits of the ID card including the social security. Similarly, 66 per cent of them did not know about the process of applying and acquiring it (Figure 5). Lack of knowledge on these different aspects was found to be the major constraints and aligns with the findings reported in Nepal by Poudyal et al (2018) and Homles et al. (2018). 


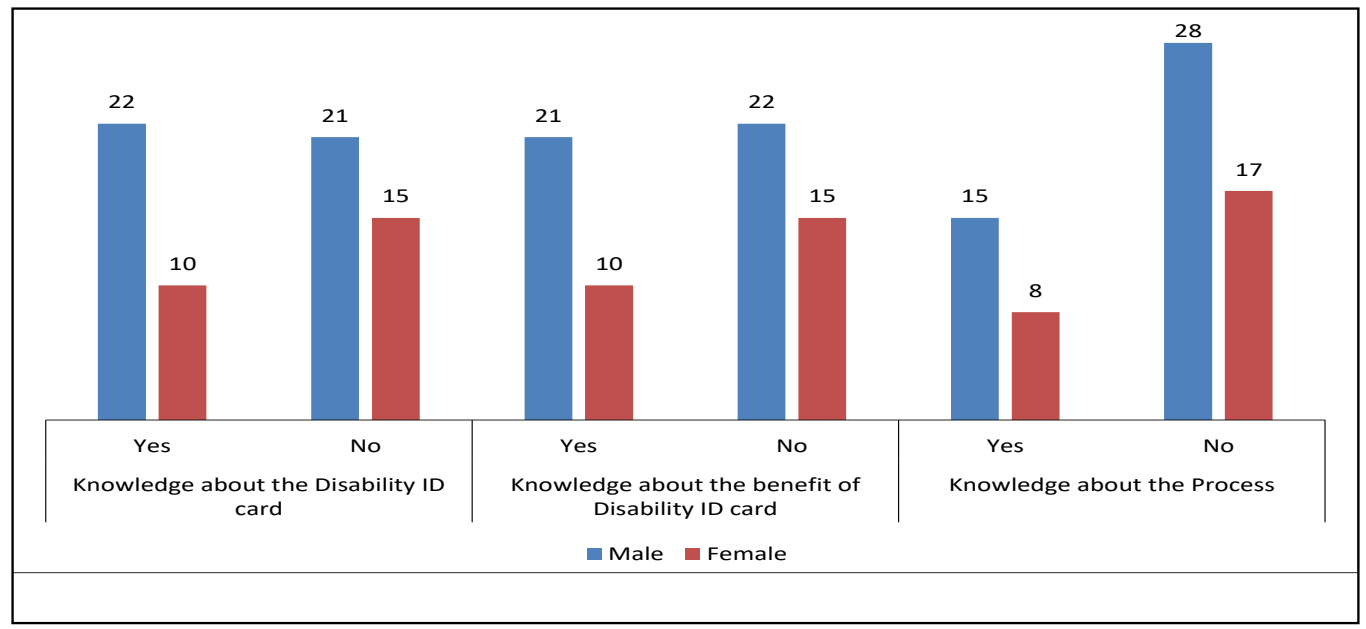

Figure 5: Number of PwDs with knowledge about ID card and its benefit and the process

\subsubsection{Constraints in getting ID card despite knowing the process}

As discussed above, out of the total PwDs, 34 per cent (23 PwDs) were aware about the process of applying and acquiring the ID card. A number of constraining factors were reported. Out of them, 39 per cent reported only one constraint while 48 per cent reported two constraints and 13 per cent reported three constraints for not applying for the ID card.

Findings show that there are seven constraining factors that restrained them in acquiring the ID despite having the knowledge on the process. One of the major constraints reported was distance from home. It was reported to be the most important constraint that involved 35 per cent of the total responses obtained. Moreover, financial resource was also reported to be another important factor

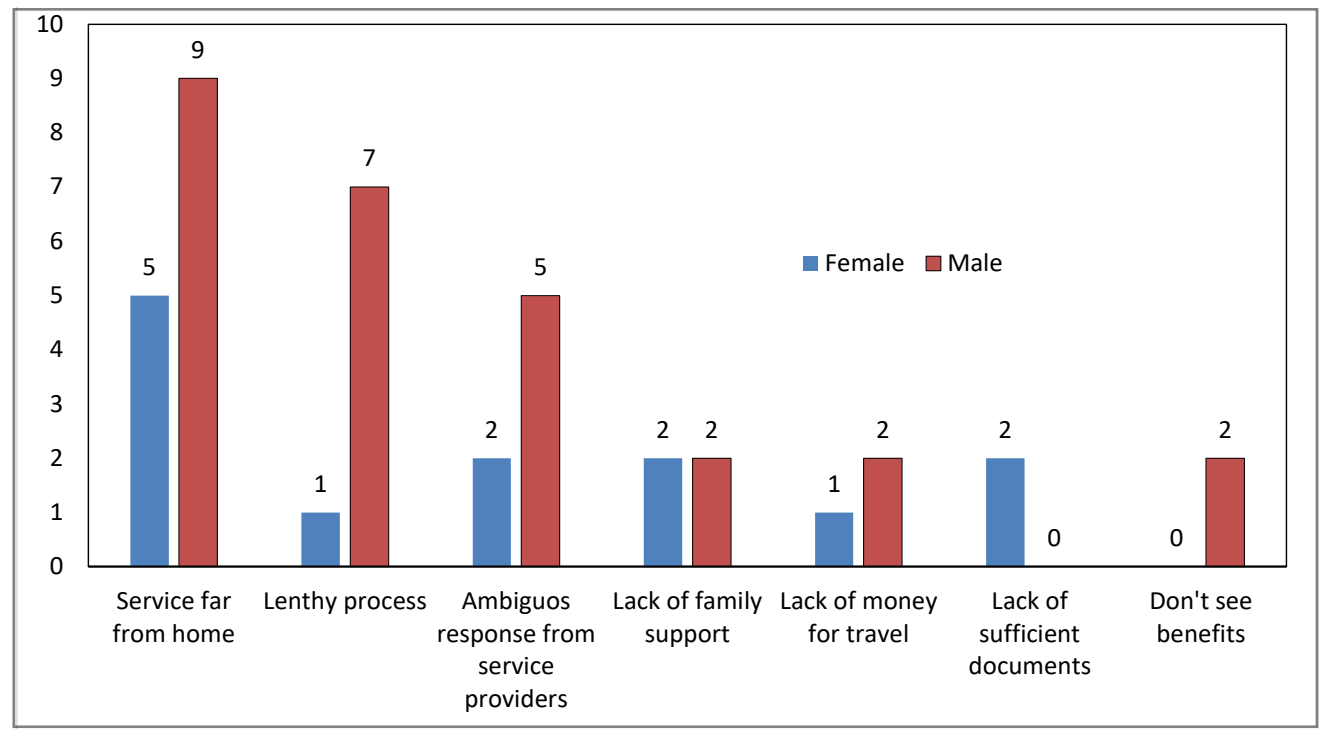

Figure 6: Constraints faced by PwDs in getting id card despite knowing the process 
constraining the application of the ID card. One of the respondents claims;

My brother has disability. We have heard about the process and the ID card. There were no service in the village during that time and we had to go to Dhulikhel to make the card. We could not return on the same day and needed sufficient money for travel, food and lodge and thus we didn't approach for the card.

Other constraints limiting the application of the ID card included lengthy process $(20 \%)$, ambiguous response from the service provider (18\%), lack of family support $(10 \%)$, lack of money for travelling to district office $(8 \%)$, and lack of required document such as citizenship certificate (Figure 6). Similar findings were reported by Morgon et al. (2019) from the study conducted in the midhill region in western Nepal. It is evident that difficulties faced as a result of long distance needed to travel was found to be the major constraint as it requires financial resources, as well as family support to overcome it. Moreover, it was observed that $\mathrm{C}$ and $\mathrm{D}$ category PwDs were found to be reluctant in applying for the card as they could not receive the social security allowance. One of the respondents claimed:

I have disability. I had gone to the district office 7 years ago. I explained about by disability to them and asked the type of card I would apply for. They had replied that I would not get Ka and Kha category type of disability card. Thus, I did not apply as I could not get any benefit.

In Nepal, before the municipality endorsed disability identification and card distribution procedure, PwDs required to travel to the district office to apply for the card. In the hills, where there was limited road access and public transport were rare, traveling to the district headquarter was not easy. Similar findings were reported by Human Rights Watch (2011). Many PwDs or their caretaker said that the process is unclear and troublesome too, as shown by NFDN's report and argued by Kidd (2017). Similarly, Morgon et al. (2019) also conclude that the requirement for extra medical documents, uncertain date of disability identification meeting at district office are some of the other major factors constraining the application of the ID card. This was also reported during the interviews. One of the respondents opined;

Our elder sister has disability. We have heard about the disability identity card and we also knew about where to apply. Seven years ago, I visited Dhulikhel (district headquarter) to ask the official about the ID card. Officials responded that she needs a doctor's recommendation to apply and they need to have a meeting to decide on whether to give the ID card or not. They also said that there is no certainty on when the next meeting will be held. After that we found the process was too lengthy and uncertain so we dropped the idea on applying for the ID.

\section{Conclusion}

Disability is one of the recently recognised issue in the Nepalese context. Although there are many types of disabilities, category $\mathrm{A}$ and $\mathrm{B}$ are entitled to the social security allowance. Identification and distribution of ID card through the government set up is important for bringing them under the social security umbrella. It has been observed that several constraints exist in terms of applying and acquiring the ID card. Prior to the federalisation in Nepal, the card used to be distributed from the district headquarter, following which the local government started distributing such ID card through municipalities/rural municipalities. Although there are several constraints in applying the card, lack of knowledge about the card, its benefits, and the processes of obtaining it are found be the major ones. Those who 
have knowledge about the ID card obtaining processes face constraints such as distance to visit the headquarter, lengthy and ambiguous processes, and lack of financial resources. However, it has been clear that easy access and proactiveness of the local government in terms of identification and distribution of the ID card has been found to be a major window of opportunity to PwDs. With this facility in place, larger number of PwDs have been identified and thereby brought under the social security system.

\section{References}

Eide A.H., Neupane, S., \& Hem, K.G. (2016). Living conditions among people with disability in Nepal.SINTEFA27656,SINTEFTechnology and Society.https://www.researchgate.net/ publication/301770844_Living_conditions among_people_ith_disabilities_in_Nepal/ link/572c77fd08ae7a42e1334261/download assessed on 8 September 2020.

Government of Nepal. (2017). The Act Relating to Rights of Persons with Disabilities, 2074 (2017), First Amendment 2075. Kathmandu: Government of Nepal. http://www.lawcommission.gov. np/en/wp-content/uploads/2019/07/TheAct-Relating-to-Rights-of-Persons-withDisabilities-2074-2017.pdf

Government of Nepal. (2018). Disability identification procedure 2018. Kathmandu: Government of Nepal.

Government of Nepal. (2019). Disability ID Card Distribution Directive 2009. Kathmandu: Government of Nepal.

Holmes, R., Samuels, F., \& Ghimire, A., (2018). Nepal's cash allowances for children with disabilities. ODI/Unicef Briefing note. https://www.odi.org/publications/11162nepal-s-cash-allowances-childrendisabilities assessed on 10 September 2020.

Human Rights Watch. (2011). Future stolen: Barriers to education for children with disabilities in Nepal. Kathmandu: Human Rights Watch. https://www.hrw.org/report/2011/08/24/ futures-stolen/barriers-education-childrendisabilities-nepal\# assessed on 11 September 2020.

Kidd, S. (2017). Social exclusion and access to social protection schemes. Journal of Development Effectiveness, 9(2), 212-244.

Morgon, L., Walsham, M., Neupane. S., Neupane, S., Pradhanga, Y., Maharjan, M., Blanchet, K., \& Kuper, H. (2019). Access to social protection among people with disabilities: Mixed methods research from Tanahun, Nepal. The European Journal of Development Research, 31, 929-956 https:// doi.org/10.1057/s41287-019-0194-3

NFDN.(2018). Supplementary information to the list of issues in relation to the initial report of the Federal Democratic Republic of Nepal on the Implementation of the Convention on the Rights of Persons with Disabilities. Kathmandu: National Federation of Disabled Nepal. https://tbinternet.ohchr.org/Treaties/ CRPD/Shared\%20Documents/NPL/INT CRPD_CSS_NPL_30065_E.docx assessed on 12 September 2020.

Nuri, RP., Ghahari, S., Aldersey, HM,, \& Huque, AS. (2020). Exploring access to governmentled support for children with disabilities in Bangladesh. PLoS ONE, 15(7), e0235439. https://doi.org/ 10.1371/journal. pone. 0235439

Poudyal, N., Banskota, M., \& Khadka, D. (2018). Disability in Nepal: Taking stock and forging a way forward. Disability Research Centre, Kathmandu University. https:// www.unicef.org/nepal/reports/disabilitynepal assessed on 14 September 2020.

Roshi Rural Municipality. (2018). Disability Identity Card Distribution Procedure of Roshi Rural Municipality. Kavre: Roshi Rural Municipality.

Schusky, E.L. (1972). Manual for kinship analysis. Second Edition USA. Holt, Rinehart and Winston, 